九州大学学術情報リポジトリ

Kyushu University Institutional Repository

\title{
Y-box binding protein-1 (YB-1) promotes cell cycle progression through CDC6-dependent pathway in human cancer cells
}

Basaki, Yuj i

Department of Pharmaceutical Oncology, Graduate School of Pharmaceutical Sciences, Kyushu University

Taguchi, Ken-ichi

Department of Pathology, Clinical Laboratory, National Kyushu Cancer Center

Izumi, Hiroto

Department of Molecular Biology, School of Medicine, University of Occupational and Environmental Health, Kitakyushu

Murakami, Yuichi

Department of Pharmaceutical Oncology, Graduate School of Pharmaceutical Sciences, Kyushu University

他

http://hdl. handle. net/2324/26618

出版情報: European Journal of Cancer. 46 (5)，pp.954-965，2010-03-01. Elsevier バージョン：

権利関係: (C) 2009 Elsevier Ltd. 
Y-box binding protein-1 (YB-1) promotes cell cycle progression through CDC6-dependent pathway in human cancer cells

Yuji Basaki, ${ }^{1}$ Ken-ichi Taguchi, ${ }^{2}$ Hiroto Izumi, ${ }^{3}$ Yuichi Murakami, ${ }^{1}$ Takuya Kubo, ${ }^{1}$ Fumihito Hosoi, ${ }^{1}$ Kosuke Watari, ${ }^{1}$ Kenji Nakano, ${ }^{4}$ Hidetoshi Kawaguchi, ${ }^{5}$ Shinji Ohno, ${ }^{5}$ Kimitoshi Kohno, ${ }^{2}$ Mayumi Ono, ${ }^{1}$ and Michihiko Kuwano ${ }^{4}$

1) Department of Pharmaceutical Oncology, Graduate School of Pharmaceutical Sciences, Kyushu University, Fukuoka, Japan

2) Department of Pathology and Clinical Laboratory, National Kyushu Cancer Center, Fukuoka, Japan

3) Department of Molecular Biology, School of Medicine, University of Occupational and Environmental Health, Kitakyushu, Japan

4) Innovation Center for Medical Redox Navigation, Kyushu University, Fukuoka, Japan

5) Department of Breast Oncology, National Kyushu Cancer Center, Fukuoka, Japan

\section{Corresponding author:}

Michihiko Kuwano, MD, PhD,

Innovation Center for Medical Redox Navigation, Kyushu University,

3-1-1, Maidashi, Higashi-ku, Fukuoka, 812-8582, Japan.

Phone/Fax: +81-92-642-6139/+81-92-642-6405

E-mail: michik@redoxnavi.med.kyushu-u.ac.jp

Running title: YB-1 regulates cell cycle through CDC6

Keywords: YB-1, CDC6, Cell cycle regulation 


\begin{abstract}
Y-box binding protein 1 (YB-1) plays pivotal roles in acquisition of global drug resistance and cell growth promotion through transcriptional activation of genes for both drug resistance and growth factor receptors. In this study, we investigated whether YB-1 is involved in regulation of the cell cycle and cell proliferation of human cancer cells. Treatment with YB-1 siRNA caused a marked suppression of cell proliferation and expression of a cell cycle related gene, CDC6 by cancer cells. Of cell cycle of cancer cells, S phase content was specifically reduced by knockdown of YB-1. The overexpression of CDC6 abrogated this inhibition of both cell proliferation and S phase entry. ChIP assay demonstrated that YB-1 binds to a Y-box located in the promoter region of the CDC6 gene. Expression of cyclin D1, CDK1 and CDK2 was also reduced with increased expression of $\mathrm{p} 21^{\mathrm{Cip} 1}$ and $\mathrm{p} 16^{\mathrm{INK} 4 \mathrm{~A}}$ when treated with YB-1 siRNA. Furthermore, the nuclear YB-1 expression was significantly associated with the level of CDC6 nuclear expression in patients with breast cancer. In conclusion, YB-1 plays an important role in cell cycle progression at G1/S of human cancer cells. YB-1 thus could be a potent biomarker for tumor growth and cell cycle in its close association with CDC6.
\end{abstract}




\section{Introduction}

The Y-box binding protein-1 (YB-1) whose cold shock domain is highly conserved plays essential roles in transcriptional and translation regulation and DNA repair. It has been involved in cell growth, apoptosis, drug resistance, embryogenesis and carcinogenesis ${ }^{[1,2]}$. Specifically, YB-1 activation enhances expression of the $\mathrm{ABC}$ transporter gene encoding $\mathrm{ABCB} 1$ (P-glycoprotein) in cultured human cancer cells in response to genotoxic stimuli ${ }^{[3,4]}$. Nuclear expression of YB-1 has been significantly correlated not only with expression of the $\mathrm{ABCB} 1$ gene in various human malignancies ${ }^{[5-11]}$ but also with expression of non-P-glycoprotein-mediated drug resistance-related genes ${ }^{[2]}$, suggesting that YB-1 could be a biomarker of global drug resistance in human cancer ${ }^{[12]}$.

Further studies have supported the involvement of YB-1 in cell proliferation. A YB-1 knockout mutation in mice caused a marked decrease in cell proliferation rates, resulted in embryonic lethality ${ }^{[13,14]}$. Transgenic expression of YB-1 causes the development of breast carcinomas with various histological types ${ }^{[15]}$ indicating that YB-1 is an oncogene. Nuclear activation of YB-1 is mediated by the essential cell growth signaling PI3K/Akt pathway ${ }^{[16-18]}$. YB-1 knockdown by its cognate siRNA inhibited cell proliferation of human breast cancer cells, prostate cancer cells, and multiple myeloma cells in culture ${ }^{[19-21]}$. YB-1 knockdown also suppressed expression of various cell cycle- and DNA replication-related genes as well as growth factor genes ${ }^{[17,22]}$. YB-1 overexpression induces EGF/TGF $\alpha$-independent cell growth and constitutive EGFR activation by human mammary cells in culture ${ }^{[23]}$. Activation of YB-1 was significantly associated with expression of EGFR family proteins such as EGFR and HER2 in patients with breast cancer ${ }^{[18,24]}$. Taken together, these studies in vitro and in vivo as well as in cancer patients strongly suggest that YB-1 is closely involved in tumor growth and malignant progression of cancer. Recently, the possible role of YB-1 in epithelial-mesenchymal transition of breast epithelial cells in its close context with Snail gene has been reported ${ }^{[25]}$.

Furthermore, concerning the possible role of YB-1 in cell cycle and DNA replication, Jurchott and colleagues have reported that nuclear YB-1 expression is induced during G1-S transition of the cell cycle ${ }^{[22]}$. During S phase in cell cycle progression, replication of cellular DNA is initiated by formation of pre-replicative complexes composed of Orc1-6, Cdt1, CDC6, and minichromosome maintenance helicase at the replication origin ${ }^{[26-28]}$. Our previous study demonstrated that expression of several cell cycle-related genes was specifically down-regulated by YB-1 knockdown in human cancer cells, and one representative 
gene that is suppressed is CDC6 ${ }^{[17]}$. CDC6 plays a key role in loading the minichromosome maintenance complexes on the origin recognition complex bound at the replication origin ${ }^{[29,30]}$. CDC6 is a target for ubiquitin-mediated proteolysis by anaphase promoting complex in G1 phase ${ }^{[31]}$. Phosphorylation of the amino terminal domain of CDC6 by cyclin-dependent kinases (CDKs) protects CDC6 from the proteolysis for S phase entry ${ }^{[26]}$. These studies indicated that the essential role of CDC6 in the initiation of DNA replication. The high level of CDC6 was also associated with oncogenic activity in human cancer ${ }^{[32,33]}$. In this study, we further examined whether CDC6 plays a role in the YB-1-promoted cell growth of human cancer cells, and how YB-1 controls expression of the CDC6 gene. The possible role of CDC6 in cell growth and cell cycle will be discussed in its close connection with YB-1 in human cancer cells. 


\section{Materials and Methods}

\subsection{Cell lines and reagents}

A549, EBC-1, MCF-7, T-47D, KPL-1, and MDA-MB231 were cultured in DMEM supplemented with 10\% fetal bovine serum. PC-9 and QG56 were cultured in RPMI supplemented with 10\% FBS v/v. Cell lines were maintained in a $5 \% \mathrm{CO}_{2}$ atmosphere at $37^{\circ} \mathrm{C}$. Anti-YB- 1 was generated by immunization of a New Zealand white rabbit with synthetic peptides (C-terminal amino acids 299-313) as described previously ${ }^{[4]}$. The YB-1 antibody could detect both cytoplasmic and nuclear YB-1. Anti-CDC6 was obtained from Proteintech Group Inc. (Chicago, IL). Anti-cyclin A, cyclin B1, cyclin D1, cyclin E, CDK1, CDK2, CDK4, $\mathrm{p} 16^{\mathrm{INK} 4 \mathrm{~A}}$ and $\mathrm{p} 21^{\mathrm{Cip} 1}$ antibodies were purchased from Cell Signaling Technology (Danvers, MA). Anti-glyceraldehyde-3-phosphate dehydrogenase (GAPDH) was purchased from TREVIGEN Inc. (Gaithersburg, MD).

\subsection{Quantitative real-time polymerase chain reaction (QRT-PCR)}

Forty eight hours after small interfering RNA (siRNA) transfection, total RNA was isolated from cell culture using ISOGEN reagent (Nippon Gene Co. Ltd., Tokyo, Japan) according to the manufacture's instructions. RNA concentration was assessed by spectrophotometry at $260 \mathrm{~nm}$. RNA was reverse-transcribed from random hexamers using AMV reverse transcriptase (Promega, Madison, WI). QRT-PCR was performed using the Real-Time PCR system 7300 (Applied Biosystems, Foster City, CA). In brief, the PCR amplification reaction mixtures $(20 \mu \mathrm{l})$ contained cDNA, primer pairs, the dual-labeled fluorogenic probe, and TaqMan Universal PCR Master Mix (Applied Biosystems). The primer pairs and probes were obtained from Applied Biosystems. The thermal cycle conditions included maintaining the reactions at $50{ }^{\circ} \mathrm{C}$ for $2 \mathrm{~min}$ and at $95{ }^{\circ} \mathrm{C}$ for $10 \mathrm{~min}$, and then alternating for 40 cycles between $95{ }^{\circ} \mathrm{C}$ for $15 \mathrm{~s}$ and $60{ }^{\circ} \mathrm{C}$ for $1 \mathrm{~min}$. The primer pairs and probe were obtained from Applied Biosystems. The relative gene expression for each sample was determined using the formula $2^{\wedge}(-\mathrm{delta} \mathrm{Ct})=2^{\wedge}(\mathrm{Ct}(\mathrm{GAPDH})-\mathrm{Ct}$ (target)), which reflected the target gene expression normalized to GAPDH levels.

\subsection{Western blot analysis}

Cells were rinsed with ice-cold PBS and lysed in a lysis buffer (pH7.5) containing $50 \mathrm{mmol} / \mathrm{L}$ Tris-HCl, 
$0.1 \% \mathrm{NP}-40 \mathrm{v} / \mathrm{v}, 350 \mathrm{mmol} / \mathrm{L} \mathrm{NaCl}, 50 \mathrm{mmol} / \mathrm{L} \mathrm{NaF}, 1 \mathrm{mmol} / \mathrm{L} \mathrm{Na} 3 \mathrm{VO}_{4}, 5 \mathrm{mmol} / \mathrm{L} \mathrm{EDTA}, 1 \mathrm{mmol} / \mathrm{L}$ PMSF, and $10 \mu \mathrm{g} / \mathrm{mL}$ each of aprotinin and leupeptin. Lysates were subjected to SDS-PAGE and blotted onto Immobilon membrane (Millipore Corp., Billerica, MA). After transfer, the membrane was incubated with the primary antibody and visualized with secondary antibody coupled to horseradish peroxidase and Supersignal West Pico Chemiluminescent Substrate (Thermo Fisher Scientific Inc.). Bands on Western blots were analyzed densitometrically using Scion Image software (version 4.0.2; Scion Corp., Frederick, MD).

\subsection{Transfection of small interfering RNA or CDC6 expression vector}

SiRNA corresponding to nucleotide sequences of YB-1 (siYB-1; 5'-GGUUCCCACCUUACUACAU-3', siYB-1'; 5'- AGAAGGUCAUCGCAACGAA-3') and CDC6

(5'-UUUACACGAGGAGAACAGGUUACGG-3') were purchased from QIAGEN Inc., (Valencia, CA) and Invitrogen (Carlsbad, CA), respectively. SiRNA duplexes were transfected using Lipofectamine RNAiMAX and Opti-MEM medium (Invitrogen) according to the manufacturer's recommendations. The expression vector for CDC6 (pCMV6/CDC6) was obtained from OriGene Technologies, Inc. (Rockville, MD). Cells were transfected with the expression vector using Lipofectamine2000 and Opti-MEM medium (Invitrogen) according to the manufacturer's recommendations.

\subsection{Cell proliferation assay}

$5 \times 10^{3}$ cells were seeded in 24-well plates and cell number in each well was counted by Z2 Coulter Particle Count and Size Analyzer (Beckman Coulter Inc., Fullerton, CA) at 3 days (breast cancer cell lines) or 2, 4, and 6 days (lung cancer cell lines) after transfection of siRNA. Results are expressed as the mean \pm S.D. of triplicate wells.

\subsection{Cell cycle analysis}

Cells were stained with propidium iodide (PI) using the Cycle Test Plus DNA Reagent kit (BD Biosciences, San Jose, CA) according to the manufacturer's recommendations. Cell distribution according to cell cycle phase was determined by measuring the DNA content using a BD FACSCalibur flow cytometer employing the Cell Quest Software. The percentage of cells in the G0/G1, S and G2/M phases was determined using 
Modifit LT software (Verity Software House Inc., Topsham, ME). Cells with hypodiploid DNA (content less than that of G0/G1-phase cells) were considered to be apoptotic (sub-G1).

\subsection{Chromatin immunoprecipitation (ChIP) assay}

ChIP assay was performed by using EZ ChIP kit (Millipore Corp.) according to the manufacturer's recommendations. Briefly, soluble chromatin from 1 x $10^{6}$ cells was incubated with $1 \mu \mathrm{g}$ of anti-YB-1 antibody. Purified DNA was dissolved in $50 \mu \mathrm{l}$ of $\mathrm{H}_{2} \mathrm{O}$ and $4 \mu \mathrm{l}$ of DNA was used for PCR analysis (32 cycles) with the following primer pairs: CDC6\#1, 5'-TCTACTGTAGTTCCCTCATTT-3' (forward) and 5'-AGGGAAGACAGCTATATAGAA-3' (reverse); CDC6\#2, 5'-ATGATGCAAATGGGTACTTTA-3' (forward) and 5'-AATCCGAATGGCCACAGCGTT-3' (reverse). PCR products were then analyzed on 2\% agarose gels and stained with ethidium bromide.

\subsection{Electrophoretic mobility shift assay (EMSA)}

The sequences of the oligonucleotides used for the probes in EMSAs were as follows: human YB-1 oligo (WT oligo), 5'-GGTGAGGCTGATTGGCTGGGCAGGA-3'; human YB-1 mutant oligo (MT oligo), 5'-GGTGAGGCTGCTGCTCTGGGCAGGA-3'. Oligonucleotides were annealed with their complementary strands. The double-stranded products were end-labeled with $\left[\alpha-{ }^{32} \mathrm{P}\right] \mathrm{dCTP}($ GE Healthcare Bio-Science) using the Klenow fragment (Takara Bio, Shiga, Japan) and purified from gels. Then, $12 \mu \mathrm{g}$ of nuclear extracts from A549 cells were incubated for $15 \mathrm{~min}$ at room temperature in a final volume of $20 \mu \mathrm{l}$ containing 10 mmol/L Tris-HCl (pH 7.9), 20 mmol/L NaCl, 1 mmol/L EDTA, 10 mmmol/L DTT, 0.1 $\mathrm{mg} / \mathrm{ml}$ bovine serum albumin (BSA), $5 \%$ glycerol v/v, $0.05 \% \mathrm{NP} 40 \mathrm{v} / \mathrm{v}, 0.05 \mathrm{mg} / \mathrm{mL}$ poly (dI-dC) and

${ }^{32} \mathrm{P}$-oligonucleotide probe. For competition assays, the appreciate competitor DNA fragments were added. The reaction mixtures were resolved by electrophoresis on a non-denaturing $4 \%$ polyacrylamide gel at $120 \mathrm{~V}$ for $120 \mathrm{~min}$, at room temperature, in $0.5 \times$ tris-borate-EDTA (TBE) buffer ( $45 \mathrm{mmol} / \mathrm{L}$ Tris base, 45 $\mathrm{mmol} / \mathrm{L}$ boric acid and $1 \mathrm{mmol} / \mathrm{L}$ EDTA). Gels were dried and analyzed using a bio-imaging analyzer (BAS-2500; Fujifilm, Tokyo, Japan).

\subsection{Immunohistochemistry}

Tissue needle core biopsy sections were taken from 93 breast cancer patients in the Department of Breast 
Oncology, National Kyushu Cancer Center, Japan, between 2002 and 2007. Tissue specimens were fixed in buffered $10 \%$ formaldehyde and embedded in paraffin. The specimens were sliced in $4 \mu \mathrm{m}$ sections and deparaffinised using xylene. The sections were then subjected to heat-induced epitope unmasking. The endogenous peroxidase activity was blocked by incubation at room temperature with $3 \%$ hydrogen peroxide $\mathrm{v} / \mathrm{v}$ in methanol for $30 \mathrm{~min}$. Non-specific antibody binding was inhibited by incubating the sections in non-specific blocking reagent for 30 min (Protein Block, Dako, Carpinteria, CA). The sections were then incubated with diluted rabbit polyclonal anti- CDC6 antibody (1:100) and rabbit polyclonal anti-YB-1 antibody (1:2000) at $4^{\circ} \mathrm{C}$ overnight. After washing, the sections were incubated with labelled polymer HRP, anti-rabbit (Envision kit, Dako), at room temperature for $60 \mathrm{~min}$, and then with 3,3'-diaminobenzidine, counterstained with hematoxylin, and mounted. Negative controls omitting the primary antibody were included. All IHC studies were evaluated by two experienced observers who were blind to the conditions of the patients. We evaluated the proportion and intensity of the immunoreactive cells of invasive breast cancer cells following the protocol used to evaluate estrogen/progesterone receptors

in breast cancer, proposed by Harvey and colleagues ${ }^{[34]}$. Cases with a total score of $>2$ and $>6$ were regarded as YB-1 and CDC6 nuclear positive, respectively.

\subsection{Statistical analysis}

Association between YB-1 and CDC6 was tested by Fisher's exact test. Statistical analysis was performed with SPSS regression Models 11.0J (SPSS Inc. Chicago, IL). 


\section{Results}

\subsection{Inhibition of cell proliferation with decreased expression of CDC6 by knockdown of YB-1}

Gene expression profiles in a breast cancer cell line comparing YB-1 siRNA-treated and control siRNA-treated cells using a high density oligonucleotide microarray showed down-regulation of a DNA replication related gene, CDC6 ${ }^{[18]}$. Consequently, we first examined the effect of YB-1 knockdown on cell proliferation of various breast and lung cancer cell lines. Treatment with YB-1 siRNA decreased the expression of YB-1 mRNA in all four breast cancer cell lines tested (Fig. 1A). Proliferation of all four breast cancer cell lines was markedly suppressed by YB-1 knockdown (Fig. 1B). Expression of CDC6 mRNA was also decreased in YB-1 siRNA-treated breast cancer cells (Fig. 1C). We further examined whether cell proliferation and expression of CDC6 mRNA were also affected by YB-1 knockdown in lung cancer cell lines. In four lung cancer cell lines, knockdown of YB-1 inhibited cell proliferation of all lung cancer cell lines (Figs. 1D and E). Exposure to YB-1 siRNA decreased expression of CDC6 mRNA to more than $50 \%$ of control siRNA in lung cancer cell lines (Fig. 1F).

\subsection{Cell cycle block at $S$ phase and expression of cell cycle-related genes in siYB-1-treated cancer cells}

CDC6 is essential for the S phase entry in cell cycle ${ }^{[26]}$. Since YB-1 knockdown caused reduction of CDC6 expression in cancer cells, we evaluated the effect of YB-1 siRNA on cell cycle by flowcytometric analysis. In breast cancer cell lines, YB-1 knockdown induced a marked decrease of S phase contents in all cancer cell lines tested (Fig. 2A). Decrease of the population of cells in S phase by YB-1 knockdown was also observed in all lung cell lines tested (Fig. 2B).

Next, we investigated the effects of YB-1 knockdown on expression profiles of genes related to the cell cycle. Treatment with YB-1 siRNA resulted in decrease of S phase contents in a dose-dependent manner (data not shown). Entry into $\mathrm{S}$ phase was strongly inhibited by $50 \mathrm{nmol} / \mathrm{L}$ of $\mathrm{YB}-1$ siRNA to approximately $20 \%$ of control siRNA-treated cells. YB- 1 knockdown by $50 \mathrm{nmol} / \mathrm{L}$ YB- 1 siRNA decreased expression of cyclin D1 and CDK2 which promote both G1 and S phase in A549 cells (Fig. 3A).

Expression of p21 $^{\mathrm{Cip} 1}$, a cell cycle inhibitor protein, was up-regulated in siYB-1-treatd cells. Expression of cyclin A, cyclin E, CDK1, CDK4 was not affected by YB-1 knockdown, while there was no apparent 
expression of $\mathrm{p} 16^{\mathrm{INK} 4 \mathrm{~A}}$ or cyclin B1. Furthermore, expression of CDC6 was markedly decreased when exposed to YB-1 siRNA (Fig. 3A). We further examined the effects of YB-1 knockdown on expression profiles of genes related to the cell cycle in breast cancer cells. Expression of both $\mathrm{p} 21^{\mathrm{Cip} 1}$ and $\mathrm{p} 16^{\mathrm{INK} 4 \mathrm{~A}}$ was up-regulated in siYB-1-treatd MCF-7 cells (Fig. 3B). Expression of CDK1 was decreased by YB-1 knockdown.

Knockdown of YB-1 decreased of CDC6 expression and suppressed S phase entry. We next examined whether both proliferation and S phase entry were inhibited by decreased expression of CDC6. Expression of CDC6 was decreased by treatment with CDC6 siRNA (Fig. 3C). Cell proliferation was susceptible to growth inhibition by CDC6 siRNA (Fig. 3D). Flowcytometric analysis showed decreased S phase contents when treated with CDC6 siRNA (Fig. 3E). We further examined the effects of different siRNAs for YB-1 (siYB-1 and siYB-1') on regulation of CDC6 expression. Since expression of CDC6 was decreased by both siRNAs, we concluded that decreased expression of CDC6 was induced by target-specific silencing of YB-1 (Fig. 3F).

\subsection{Exogenous introduction of CDC6 gene abrogates YB-1 siRNA-induced inhibition of cell proliferation}

To determine whether CDC6 is directly involved in inhibition of both cell proliferation and S phase entry induced by YB-1 knockdown, we performed double transfection experiments of YB-1 siRNA and a CDC6 expression vector. Figure 4A showed down-regulation of YB-1 expression by treatment with YB-1 siRNA, and up-regulation of CDC6 by transfection with the CDC6 expression vector. Inhibition of both cell proliferation and S phase entry by YB-1 knockdown was reversed by overexpression of CDC6 (Figs. 4B and C). We also confirmed if YB-1 interacts with 5'-flanking regulatory region of CDC6 gene which contains a Y-box (inverted CCAAT) element by ChIP assay. The ChIP assay confirmed that YB-1 was observed in the promoter region of CDC6 gene in vivo (Fig. 4D). To confirm whether YB-1 could bind to Y-box, nuclear extracts prepared from A549 cells was hybridized with labeled oligonucleotide probe containing Y-box sequence. Figure 4E showed binding of YB-1 to Y-box element by electrophoretic mobility shift assay.

\subsection{Immunostaining of YB-1 and CDC6 in human breast cancers}


To examine whether nuclear expression of YB-1 is associated with CDC6 expression in human breast cancers, immunohistochemical analysis was performed. Clinical and pathological characteristics at diagnosis are summarized in Table 1. Representative images of immunohistochemical staining showed a case with the presence of nuclear YB-1 and CDC6, and another case with the absence of nuclear YB-1 and CDC6 (Fig. 5). Nuclear expressions of YB-1 was detected in 41 of 93 patients (44\%; nuclear YB-1 positive), and that of CDC6 was in 26 of 93 patients (28\%; nuclear CDC6 positive), respectively. There was significant correlation between the expression of YB-1 and CDC6 in nucleus of cancer cells $(P=0.012$, Table 2). 


\section{Discussion}

In our present study, we observed a marked inhibition of cell proliferation of almost all cancer cell lines tested by knockdown of YB-1, consistent with previous studies of human prostate, breast and multiple myeloma cell lines ${ }^{[19-21]}$. YB-1 is thus a potent mitogenic biomarker of cell growth of cancer cells. Furthermore, we demonstrated specifically decreased population at $\mathrm{S}$ phase of cancer cells by knockdown of YB-1. Of various cell cycle-related genes, down-regulation of cyclin D1 and up-regulation of p21 $1^{\text {Cip } 1}$ both of which are related to the G1 phase were observed by YB-1 knockdown. Chatterjee and colleagues have reported a relevant study that cyclin D1 is specifically down-regulated by YB-1 knockdown in human multiple myeloma cells, resulting in a marked decrease of viable cells, suggesting that YB-1

knockdown-induced cell growth arrest is due to decreased expression of cyclin D1 ${ }^{[21]}$. On the other hand, overexpression of YB-1 facilitated expression of both cyclin A and cyclin B1 in breast cancer cells ${ }^{[22]}$. Our previous study demonstrated up-regulation of cyclin A and down-regulation of cyclin B1 in breast cancer cells treated with YB-1 siRNA ${ }^{[18]}$, and also up-regulation of cyclin B1 and B2 in ovarian cancer cells by YB-1 siRNA ${ }^{[17]}$. However, expression of both cyclin A and cyclin B1 was not affected by YB-1 knockdown in lung cancer cells (this study), suggesting that regulatory role of YB-1 in expression of cyclin A and/or cyclin B is dependent on cell types and/or cell lines.

Up-regulation of $\mathrm{p} 21^{\mathrm{Cip} 1}$, an inhibitor of cyclin D/CDK4 complexes, was also accompanied by down-regulation of cyclin D1 in YB-1 siRNA-treated cells. In our present study, however, there was no change in expression levels of CDK4 by YB-1 knockdown. Of CDK family proteins, expression of S phase-related gene, such as CDK2, was down-regulated by YB-1 siRNA. Cell cycle progression is controlled by an interplay of cyclins and CDKs, and activity of CDKs is positively and negatively regulated by cyclins and CDK inhibitors, respectively ${ }^{[35]}$. Cyclin D1 is induced in response to mitogenic signals and assembles with its catalytic partner, CDK4, as cell cycle progress through G1 phase ${ }^{[36]}$. Furthermore, it is well known that down-regulation of CDK4 activity and up-regulation of CDK inhibitors causes G1 phase $\operatorname{arrest}^{[37,38]}$. Activation of cyclin E/CDK2 and cyclin A/CDK2 was observed in G1-S transition phase. Thus, the alteration in expression profile of certain genes related to cell cycle-related by knockdown of YB-1 also indicated that YB-1 may play a key role in S phase entry during cell cycle progression.

Concerning the possible mechanism underlying YB-1 knockdown-induced inhibition of cell proliferation, we first observed marked inhibition of CDC6 expression by YB-1 knockdown in lung and 
breast cancer cells. In our previously report, there was no decrease expression of CDC6 in YB-1 siRNA-treated ovarian cancer cells assayed by DNA microarray, suggesting that YB-1-induced regulation of $C D C 6$ gene expression depends upon cancer cell types and/or types of stimuli. CDC6, which is stabilized by phosphorylation of its $\mathrm{NH}_{2}$-terminal domain, is known to recruit minichromosome maintenance helicase at the DNA replication origin ${ }^{[26-28]}$, and CDC6 knockdown inhibits cell proliferation with a concomitant decrease with cell population at S phase ${ }^{[39]}$. Decreased accumulation of cells at $\mathrm{S}$ phase as well as inhibition of cell proliferation was most prominent in one cancer cell line (A549) (see Figs. 3D and E) as compared with other cell lines when treated with CDC6 siRNA (data not shown). S phase entry could be more dependent upon CDC6 in this cell line than other cell lines examined, suggesting involvement of other factor(s) that may compensate for the decrease in CDC6. Exogenous introduction of CDC6 gene resulted in significant increases of viable cells and the fraction of the cell population at S phase when treated with YB-1 siRNA. Furthermore, we found that YB-1 was bound to its consensus Y-box sequence in the promoter region for CDC6 gene. We thus favor an idea that cell cycle G1/S and cell proliferation are at least, in part, due to CDC6 in the cancer cell lines examined.

Nuclear expression and/or activation of YB-1 is significantly correlated with poor prognosis of cancer patients with ovarian cancer ${ }^{[7,11]}$, soft tissue tumors such as synovial sarcoma and rhabdomyosarcoma ${ }^{[6,8]}$, lung cancer ${ }^{[40,41]}$, breast cancer ${ }^{[5,18]}$, pediatric glioblastoma ${ }^{[42]}$, and multiple myeloma ${ }^{[21]}$. Although nuclear YB-1 expression is well known to be closely associated with ABCB1-mediated drug resistance in various human malignancies ${ }^{[2,12]}$, it remains unknown if $\mathrm{ABCB} 1$-mediated drug resistance is involved in the close correlation between YB-1 and poor prognosis. In this study, nuclear expression of YB-1 was significantly correlated with CDC6 expression in breast cancer. Further study should be required to understand whether CDC6 expression could play a role in YB-1-triggered poor prognosis in various human malignancies.

In conclusion, expression of a key protein of G1/S phase, CDC6, is under control by YB-1 in cancer cells, and we present evidence that expression of CDC6 plays an essential role in the cell proliferation and cell cycle G1/S induced by YB-1. The YB-1/CDC6 axis will provide novel molecular pathway for therapeutic treatment of human malignant tumors. 


\section{Acknowledgments}

This research was supported by a grant-in-aid for Scientific Research on Priority Areas, Cancer, from the Ministry of Education, Culture, Sports, Science and Technology of Japan (M.O.), and by the 3rd Term Comprehensive Control Research for Cancer from the Ministry of Health, Labor and Welfare, Japan (M.K.).

This study was also supported, in part, by the Formation of Innovation Center for Fusion of Advanced Technologies, Kyushu University, Japan (M.K., and M.O.). We thank R.G. Deeley (Cancer Research Institute at Queen's University) for fruitful discussions

\section{Conflict of interest statement}

None declared. 


\section{References}

1. Matsumoto K, Wolffe AP. Gene regulation by Y-box proteins: coupling control of transcription and translation. Trends Cell Biol 1998; 8: 318-23.

2. Kohno K, Izumi H, Uchiumi T, Ashizuka M, Kuwano M. The pleiotropic functions of the Y-box-binding protein, YB-1. Bioessays 2003; 25: 691-8.

3. Asakuno K, Kohno K, Uchiumi T, et al. Involvement of a DNA binding protein, MDR-NF1/YB-1, in human MDR1 gene expression by actinomycin D. Biochem Biophys Res Commun 1994; 199: 1428-35.

4. Ohga T, Koike K, Ono M, et al. Role of the human Y box-binding protein YB-1 in cellular sensitivity to the DNA-damaging agents cisplatin, mitomycin C, and ultraviolet light. Cancer Res 1996; 56: $4224-8$.

5. Bargou RC, Jürchott $\mathrm{K}$, Wagener $\mathrm{C}$, et al. Nuclear localization and increased levels of transcription factor YB-1 in primary human breast cancers are associated with intrinsic MDR1 gene expression. Nat Med 1997; 3: 447-50.

6. Oda Y, Sakamoto A, Shinohara N, et al. Nuclear expression of YB-1 protein correlates with P-glycoprotein expression in human osteosarcoma. Clin Cancer Res 1998; 4: 2273-7.

7. Kamura T, Yahata H, Amada S, et al. Is nuclear expression of Y-box binding protein-1 a new prognostic factor in ovarian serous adenocarcinoma? Cancer 1999; 85: 2450-4.

8. Oda Y, Ohishi Y, Saito T, et al. Nuclear expression of Y-box-binding protein-1 correlates with P-glycoprotein and topoisomerase II alpha expression, and with poor prognosis in synovial sarcoma. $J$ Pathol 2003; 199: 251-258.

9. Huang X, Ushijima K, Komai K, et al. Co-expression of Y-box binding protein-1 and P-glycoprotein as a prognostic marker for survival in epithelial ovarian cancer. Gynecol Oncol 2004; 93: 287-91.

10. Giménez-Bonafé P, Fedoruk MN, Whitmore TG, et al. YB-1 is upregulated during prostate cancer tumor progression and increases P-glycoprotein activity. Prostate 2004; 59: 337-49.

11. Oda Y, Ohishi Y, Basaki Y, et al. Prognostic implications of the nuclear localization of Y-box-binding protein-1 and CXCR4 expression in ovarian cancer: their correlation with activated Akt, LRP/MVP and P-glycoprotein expression. Cancer Sci 2007; 98: 1020-6. 
12. Kuwano M, Oda Y, Izumi H, et al. The role of nuclear Y-box binding protein 1 as a global marker in drug resistance. Mol Cancer Ther 2004; 3: 1485-92.

13. Lu ZH, Books JT, Ley TJ. YB-1 is important for late-stage embryonic development, optimal cellular stress responses, and the prevention of premature senescence. Mol Cell Biol 2005; 25: 4625-37.

14. Uchiumi T, Fotovati A, Sasaguri T, et al. YB-1 is important for an early stage embryonic development: neural tube formation and cell proliferation. J Biol Chem 2006; 281: 40440-9.

15. Bergmann S, Royer-Pokora B, Fietze E, et al. YB-1 provokes breast cancer through the induction of chromosomal instability that emerges from mitotic failure and centrosome amplification. Cancer Res 2005; 65: 4078-87.

16. Sutherland BW, Kucab J, Wu J, et al. Akt phosphorylates the Y-box binding protein 1 at Ser 102 located in the cold shock domain and affects the anchorage-independent growth of breast cancer cells. Oncogene 2005; 24: 4281-92.

17. Basaki Y, Hosoi F, Oda Y, et al. Akt-dependent nuclear localization of Y-box-binding protein 1 in acquisition of malignant characteristics by human ovarian cancer cells. Oncogene 2007; 26: 2736-46.

18. Fujii T, Kawahara A, Basaki Y, et al. Expression of HER2 and estrogen receptor alpha depends upon nuclear localization of Y-box binding protein-1 in human breast cancers. Cancer Res 2008; 68: 1504-12.

19. Lee C, Dhillon J, Wang MY, et al. Targeting YB-1 in HER-2 overexpressing breast cancer cells induces apoptosis via the mTOR/STAT3 pathway and suppresses tumor growth in mice. Cancer Res 2008; 68: 8661-6.

20. Shiota M, Izumi H, Onitsuka T, et al. Twist promotes tumor cell growth through YB-1 expression. Cancer Res 2008; 68: 98-105.

21. Chatterjee M, Rancso C, Stühmer T, et al. The Y-box binding protein YB-1 is associated with progressive disease and mediates survival and drug resistance in multiple myeloma. Blood 2008; 111: 3714-22.

22. Jurchott K, Bergmann S, Stein U, et al. YB-1 as a cell cycle-regulated transcription factor facilitating cyclin A and B1 gene expression. J Biol Chem 2003; 278: 27988-96.

23. Berquin IM, Pang B, Dziubinski ML, et al. Y-box-binding protein 1 confers EGF independence to human mammary epithelial cells. Oncogene 2005; 24: 3177-86. 
24. Wu J, Lee C, Yokom D, et al. Disruption of the Y-box binding protein-1 results in suppression of the epidermal growth factor receptor and HER-2. Cancer Res 2006: 66: 4872-9.

25. Evdokimova $\mathrm{V}$, Tognon $\mathrm{C}, \mathrm{Ng} \mathrm{T}$, et al. Translational activation of snail1 and other developmentally regulated transcription factors by YB-1 promotes an epithelial-mesenchymal transition. Cancer Cell 2009; 15: 402-15.

26. Mailand N, Diffley JF. CDKs promote DNA replication origin licensing in human cells by protecting Cdc6 from APC/C-dependent proteolysis. Cell 2005; 122: 915-26.

27. Takeda DY, Shibata Y, Shibata Y, Parvin JD, Dutta A. Recruitment of ORC or CDC6 to DNA is sufficient to create an artificial origin of replication in mammalian cells. Genes Dev 2005; 19: 2827-36.

28. Randell JC, Bowers JL, Rodriguez, HK, Bell SP. Sequential ATP hydrolysis by Cdc6 and ORC directs loading of the Mcm2-7 helicase. Mol Cell 2006; 21: 29-39.

29. Cook JG, Park CH, Burke TW, et al. Analysis of Cdc6 function in the assembly of mammalian prereplication complexes. Proc Natl Acad Sci USA 2002; 99: 1347-52.

30. Stillman B. Origin recognition and the chromosome cycle. FEBS Lett 2005; 579: 77-84.

31. Petersen BO, Wagener C, Marinoni F, et al. Cell cycle- and cell growth-regulated proteolysis of mammalian CDC6 is dependent on APC-CDH1. Genes Dev 2000; 14: 2330-43.

32. Gonzalez S, Klatt P, Delgado S, et al. Oncogenic activity of Cdc6 through repression of the INK4/ARF locus. Nature 2006; 440: 702-6.

33. Romagnoli S, Fasoli E, Vaira $\mathrm{V}$, et al. Identification of potential therapeutic targets in malignant mesothelioma using cell-cycle gene expression analysis. Am J Pathol 2009; 174: 762-70.

34. Harvey JM, Clark GM, Osborne CK, Allred DC. Estrogen receptor status by immunohistochemistry is superior to the ligand-binding assay for predicting response to adjuvant endocrine therapy in breast cancer. J Clin Oncol 1999; 17: 1474-81.

35. Sherr CJ, Roberts JM. CDK inhibitors: positive and negative regulators of G1-phase progression. Genes Dev 1999; 13: 1501-12.

36. Sherr CJ. Mammalian G1 cyclins. Cell 1993; 73: 1059-65.

37. Ball KL, Lain S, Fâhraeus R, Smythe C, Lane DP. Cell-cycle arrest and inhibition of Cdk4 activity by small peptides based on the carboxy-terminal domain of p21WAF1. Curr Biol 1997; 7: 71-80. 
38. Chen WJ, Chang CY, Lin JK. Induction of G1 phase arrest in MCF human breast cancer cells by pentagalloylglucose through the down-regulation of CDK4 and CDK2 activities and up-regulation of the CDK inhibitors p27(Kip) and p21(Cip). Biochem Pharmacol 2003; 65: 1777-85.

39. Feng L, Barnhart JR, Seeger RC, et al. Cdc6 knockdown inhibits human neuroblastoma cell proliferation. Mol Cell Biochem 2008; 311: 189-197.

40. Shibahara K, Sugio K, Osaki T, et al. Nuclear expression of the Y-box -binding protein, YB-1 as a novel marker of disease progression in non-small cell lung cancer. Clin Cancer Res 2001; 7: 3151-5.

41. Kashihara M, Azuma K, Kawahara A, et al. Nuclear Y-box binding protein-1, a predictive marker of prognosis, is correlated with expression of HER2/ErbB2 and HER3/ErbB3 in non-small cell lung cancer. J Thorac Oncol 2009; 4: 1066-74.

42. Faury D, Nantel A, Dunn SE, et al. Molecular profiling identifies prognostic subgroups of pediatric glioblastoma and shows increased YB-1 expression in tumors. J Clin Oncol 2007; 25: 1196-208. 


\section{Figure Legends}

Figure 1. Effects of YB-1 siRNA on cell proliferation and CDC6 expression in breast and lung cancer cell lines. (A) Knockdown of YB-1 by treatment of YB-1 siRNA was determined by QRT-PCR in breast cancer cell lines. (B) Proliferation of breast cancer cell lines was suppressed by treatment of YB-1 siRNA. (C) Effect of YB-1 knockdown on expression of CDC6 in breast cancer cell lines. (D) Knockdown of YB-1 by treatment of YB-1 siRNA was determined by QRT-PCR in lung cancer cell lines. (E) Proliferation of lung cancer cell lines was suppressed by treatment of YB-1 siRNA. (F) Effect of YB-1 knockdown on expression of CDC6 in lung cancer cell lines. Data are expressed as the mean \pm S.D.

Figure 2. Decrease of S phase contents by YB-1 knockdown in breast (A) and lung (B) cancer cell lines. Cells were treated with siRNA for $48 \mathrm{~h}$, and then detached from substratum by limited trypsin digestion and single cell suspension was used for propidium iodide staining. DNA-content in single cells was measured using the BD FACSCaliber flow cytometer. Data are expressed as the mean \pm S.D.

Figure 3. Effect of YB-1 knockdown on expression profiles of genes related to cell cycle and inhibition of both cell proliferation by CDC6 siRNA. (A, B) Effect of YB-1 knockdown on expression of cyclin D1, CDK4, p21 ${ }^{\mathrm{Cip} 1}$, cyclin E, CDK2, p16 ${ }^{\mathrm{INK} 4 \mathrm{~A}}$, cyclin A, cyclin B1, and CDK1 was analyzed by immunoblotting. Cells were incubated with $50 \mathrm{nmol} / \mathrm{L}$ siRNA for $48 \mathrm{~h}$, and lysates were prepared. Levels of selected gene expression were measured densitometrically (A; A549 cells, B; MCF-7 cells). (C) Knockdown of CDC6 by treatment of CDC6 siRNA was determined by immunoblotting. Cells were incubated with $50 \mathrm{nmol} / \mathrm{L}$ siRNA for $48 \mathrm{~h}$, and lysates were prepared. (D) Effect of CDC6 siRNA on proliferation of A549 cells. (E) Decrease of S phase contents by CDC6 knockdown in lung cancer cells. Data are expressed as the mean \pm S.D. (F) Effects of different siRNAs for YB-1 (siYB-1 and siYB-1') on CDC6 expression in A549 cells. Cells were incubated with $50 \mathrm{nmol} / \mathrm{L}$ siRNA for $48 \mathrm{~h}$, and lysates were prepared.

Figure 4. CDC6 canceled YB-1 siRNA-induced suppression of both proliferation and S phase entry. (A) A549 cells were transfected with indicated siRNA $(50 \mathrm{nmol} / \mathrm{L})$ and plasmid $(2 \mu \mathrm{g})$ for $48 \mathrm{~h}$, and lysates 
were prepared. Expression of YB-1 and CDC6 was analyzed by immunoblotting. (B) Effect of CDC6 over expression of YB-1 knockdown-induced inhibition of cell proliferation. (C) Effect of CDC6 over expression on S phase entry. Conditions of cell harvesting and staining as in Figure 2. Data are expressed as the mean \pm S.D. (D) The in vivo YB-1 binding to the CDC6 promoter was analyzed by ChIP assay. Schematic representation of the promoter region of CDC6 gene. Black boxes and arrows indicate CCAAT box and PCR primer regions, respectively. Arrowheads indicate PCR products (393 bp and $383 \mathrm{bp}$ ). (E) Nuclear extracts from A549 cells was hybridized with radioactive labeled Y-box oligonucleotide probes, 5'-TCGACTTCCCAAGAACAGCA-3'. The samples were separated by non-denaturing PAGE and the bands were detected by autoradiography.

Figure 5. Immunohistochemical analysis of YB-1 and CDC6 in breast cancer patients. Two clinical samples of patients with YB-1 positive specimens (case1) and YB-1 negative specimens (case 2). Expression of both YB-1 and CDC6 was recognized in two patterns: nuclear positive or negative. 
Table 1. Clinical and pathological characteristics of 93 patients with breast cancers.

\begin{tabular}{lc}
\hline Characteristic & $\mathrm{N}$ \\
\hline Age (years) & $18-73$ (mean: 48.2)
\end{tabular}

Histological grade
I, II
61

III

32

Menopausal status

Pre

Post

Tumor size

$\leq 5$

$>5$

30

Lymph node metastasis

$\begin{array}{ll}\text { Absent } & 31 \\ \text { Present } & 62\end{array}$

Nuclear grade

I, II 61

III 32 
Table 2 Correlation between nuclear YB-1 expression and CDC6 expression in human breast cancers.

\section{CDC6}

YB-1

Positive $(\mathrm{N}=26)$

Negative $(\mathrm{N}=67)$

\begin{tabular}{lcc}
\hline Positive $(\mathrm{N}=41)$ & $17(41.5 \%)$ & $24(58.5 \%)$ \\
Negative $(\mathrm{N}=52)$ & $9(17.3 \%)$ & $43(82.7 \%)$
\end{tabular}

Fisher's exact $P=0.012$. 
Figure 1A, B, C

A

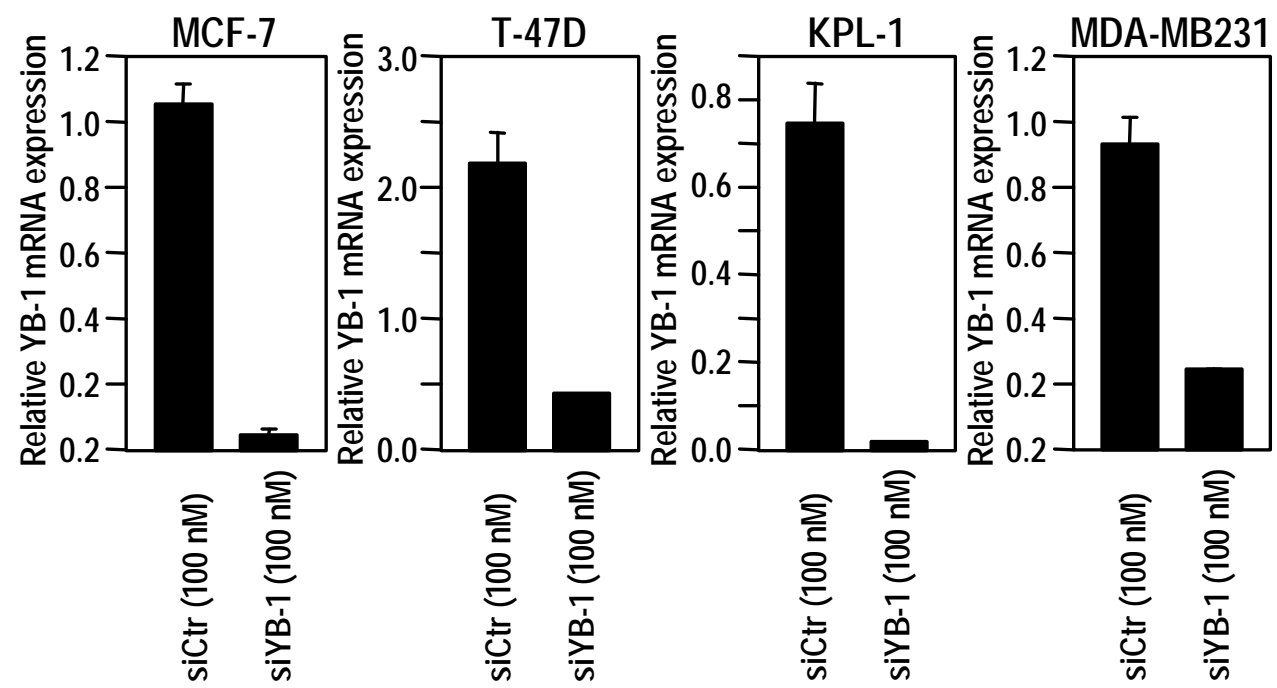

B
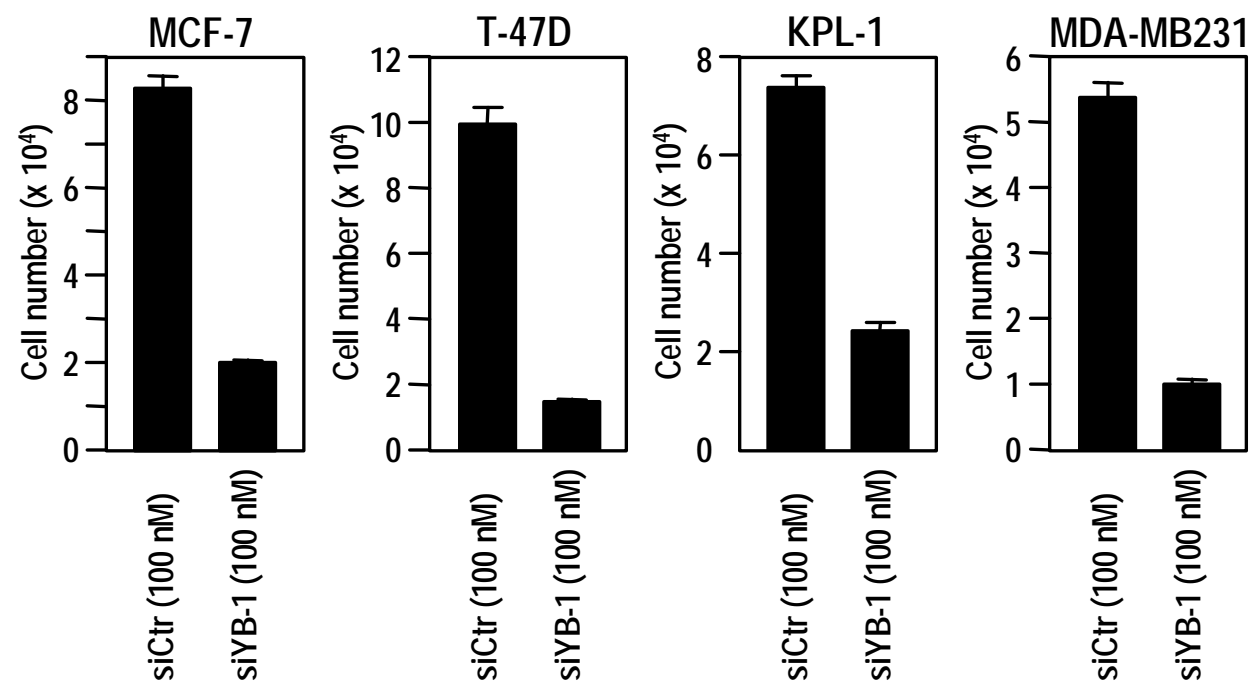

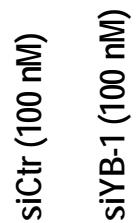

C

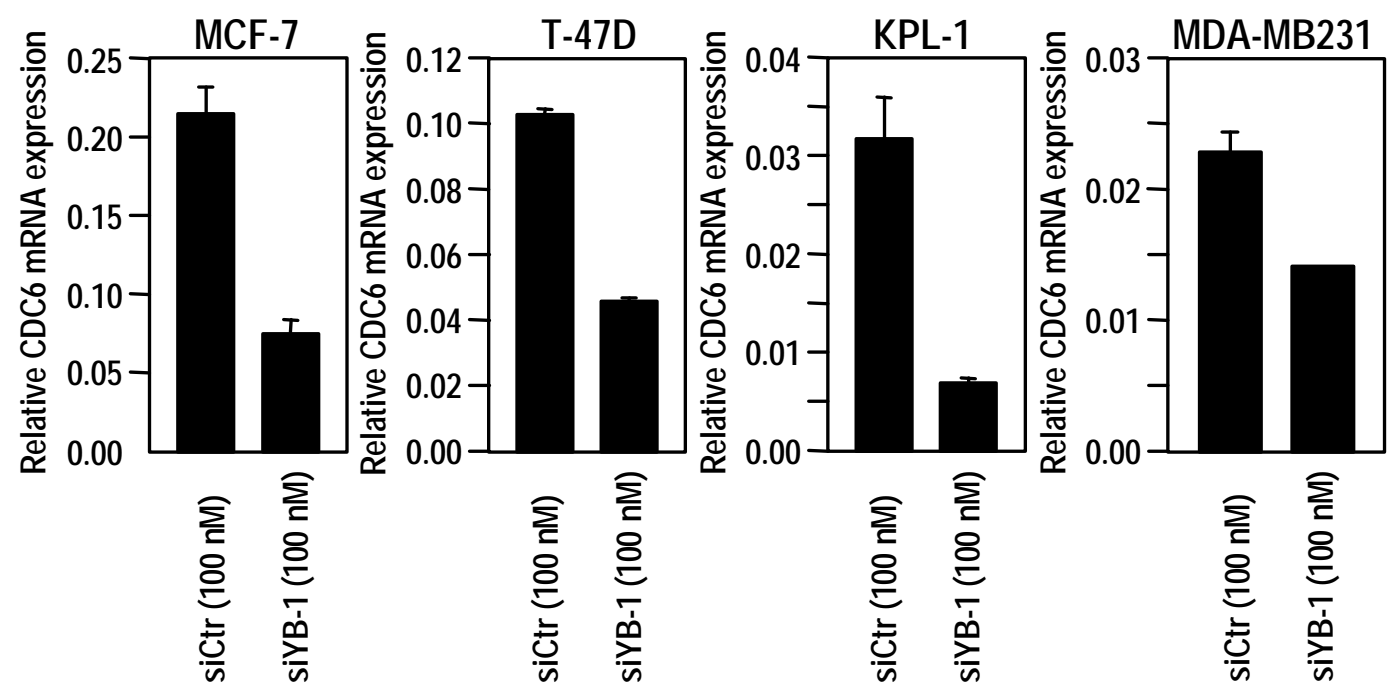


Figure 1D, E, F

D

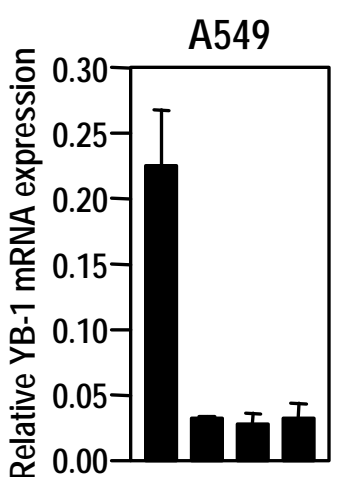

$\sum_{i=1} \sum_{\underline{i}}$

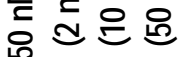

हैं

泫

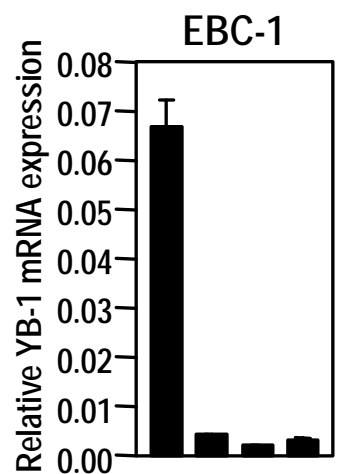

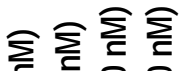

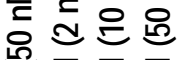

帝 它 离

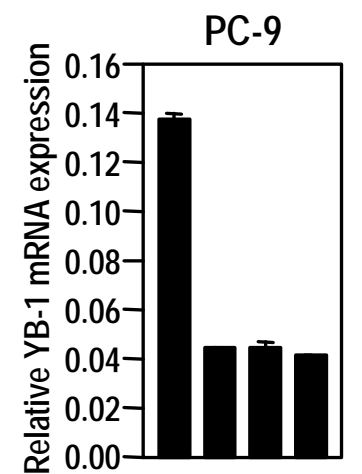

$\sum_{i=1} \sum_{i=1}$

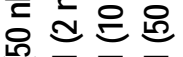

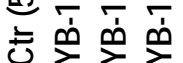

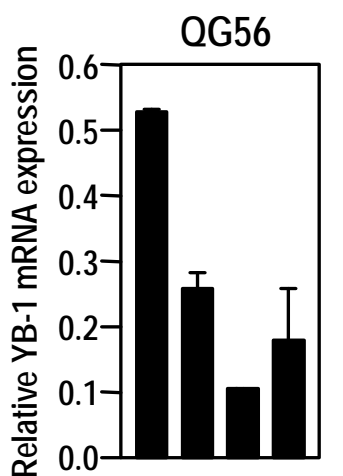

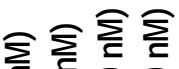

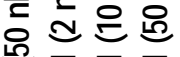

的

旁 $\sum_{\bar{\omega}}^{\infty} \sum_{\bar{\omega}}^{\infty} \sum_{\bar{\omega}}^{\infty}$

E
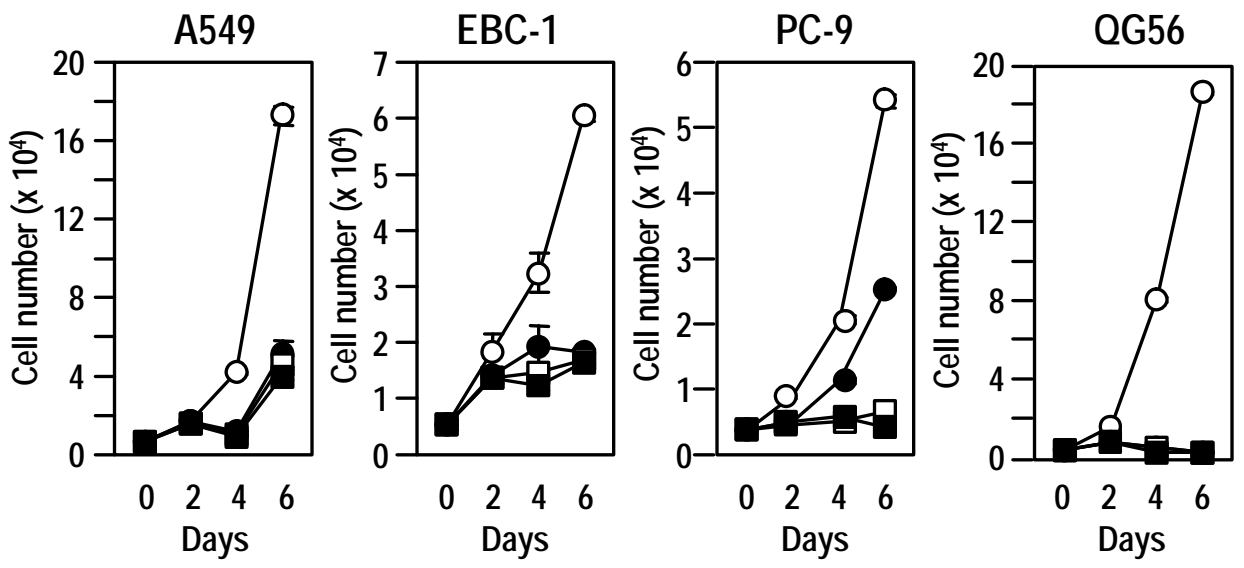

-o siCtr

$\rightarrow \operatorname{siYB}-1$ (2 nM)

$\rightarrow$ siYB-1 (10 nM)

$\rightarrow-\operatorname{siYB}-1$ (50 nM)

F

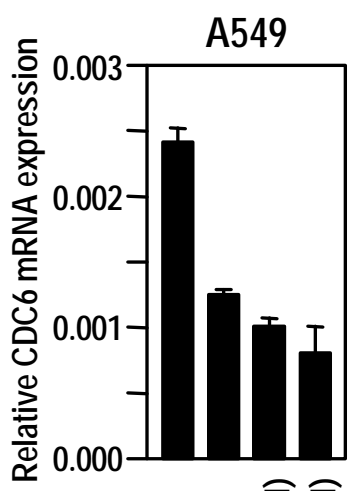

依 $\sum_{i=1}$

边

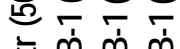

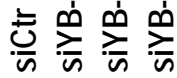
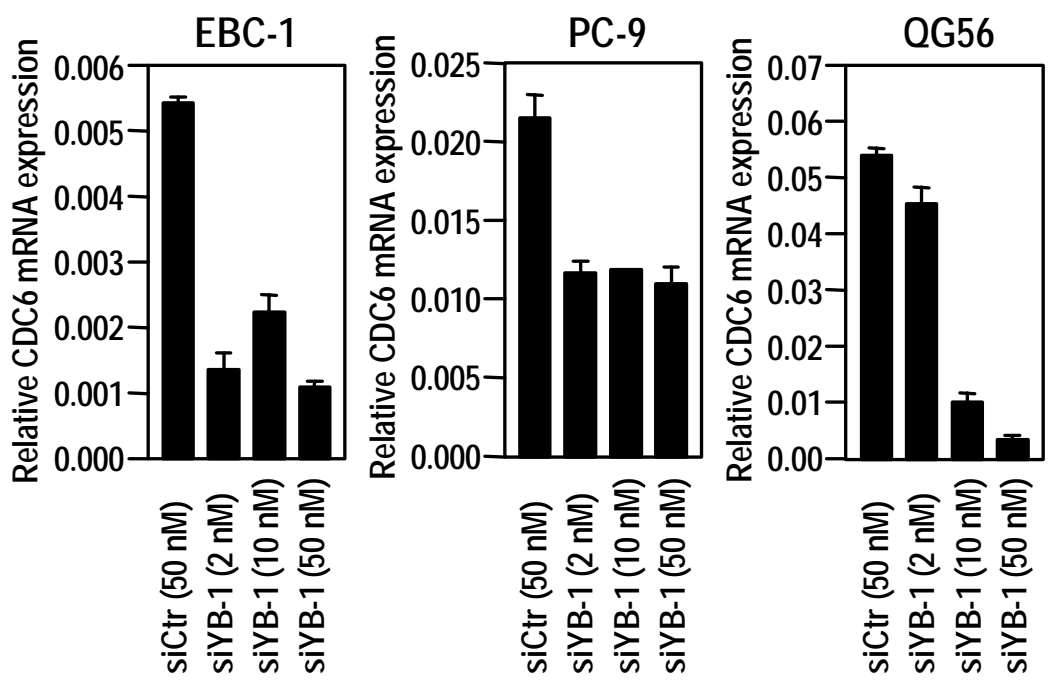
Figure 2A

A
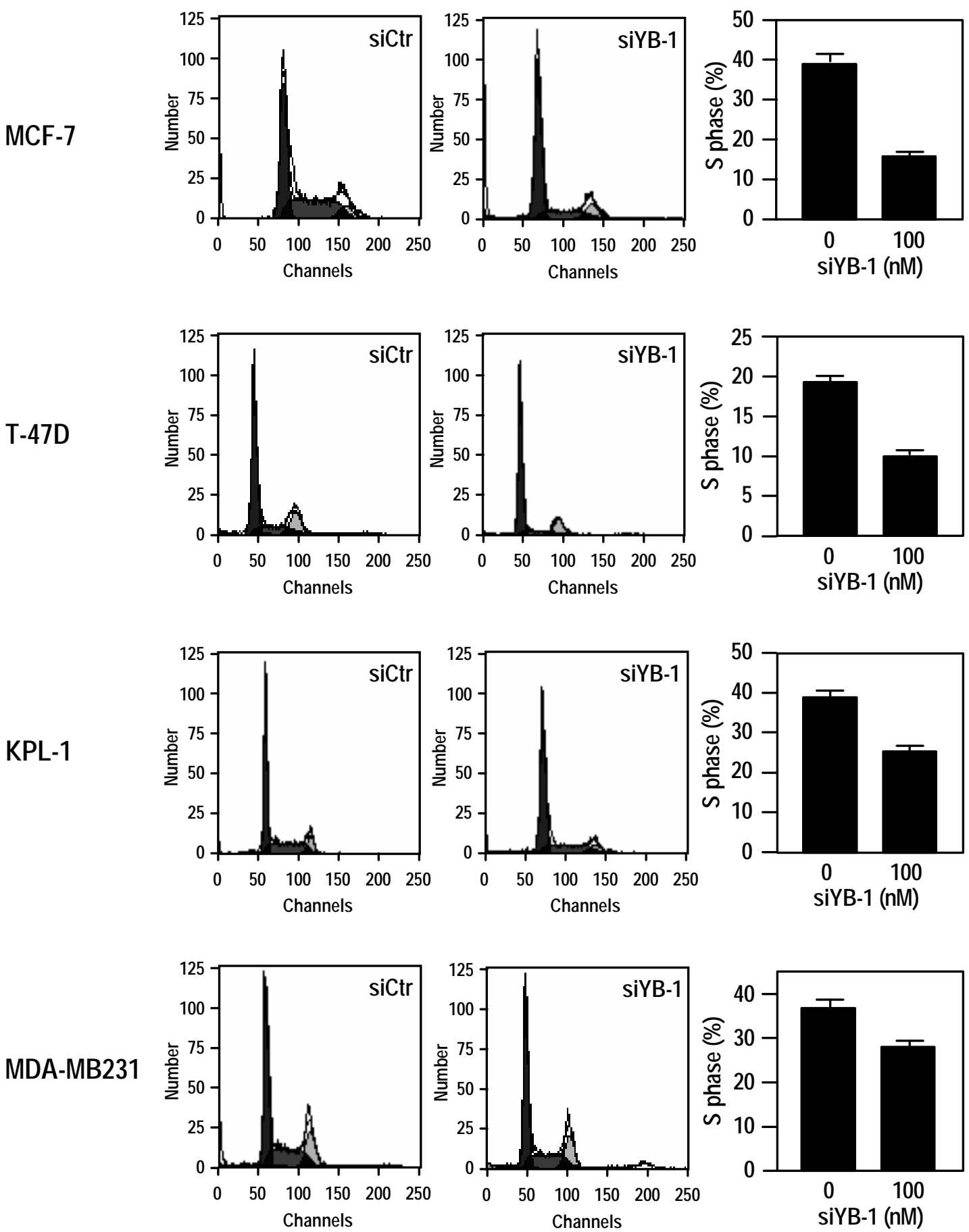
Figure 2B

B
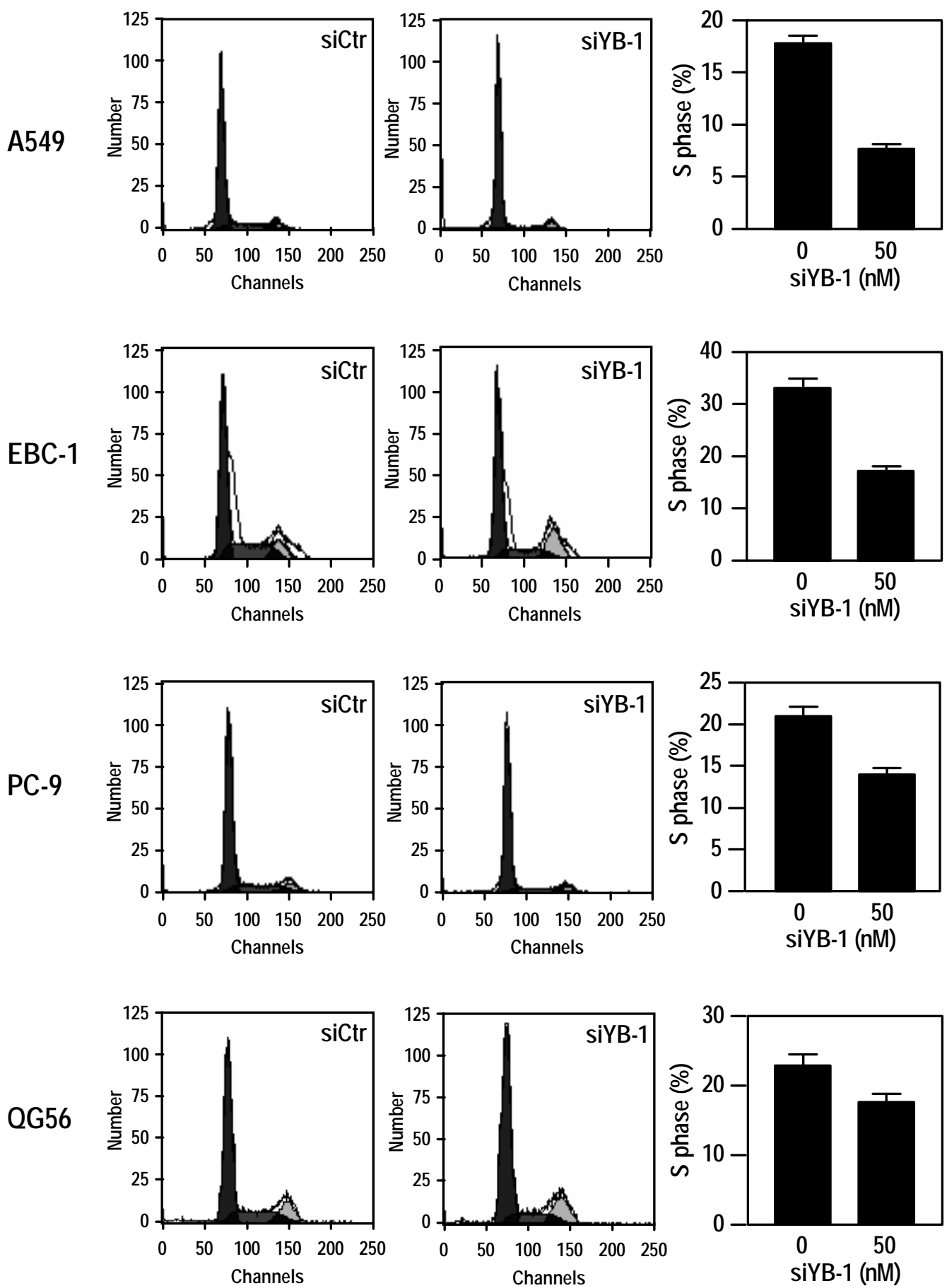
Figure $3 \mathrm{~A}, \mathrm{~B}$

A
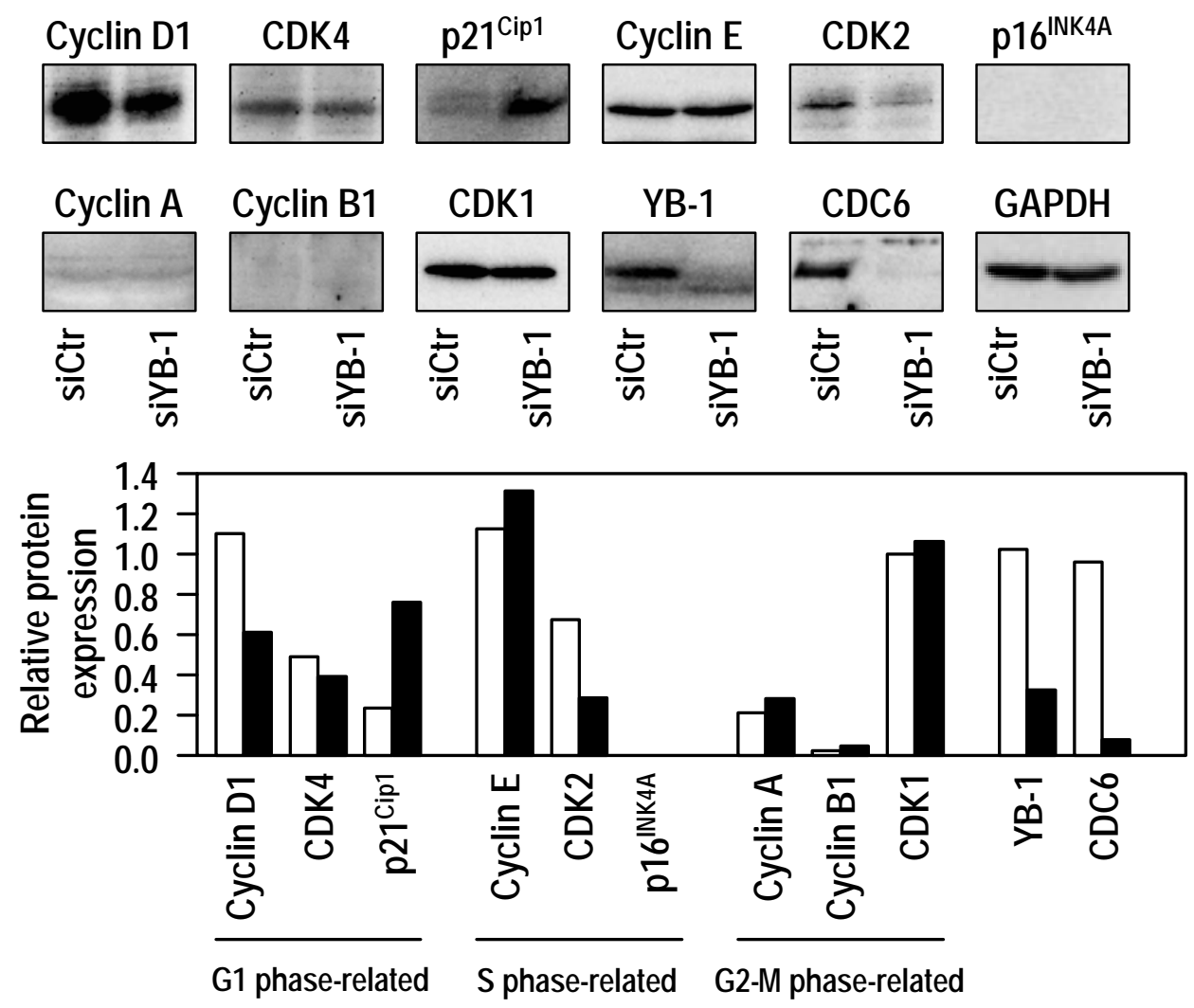

B
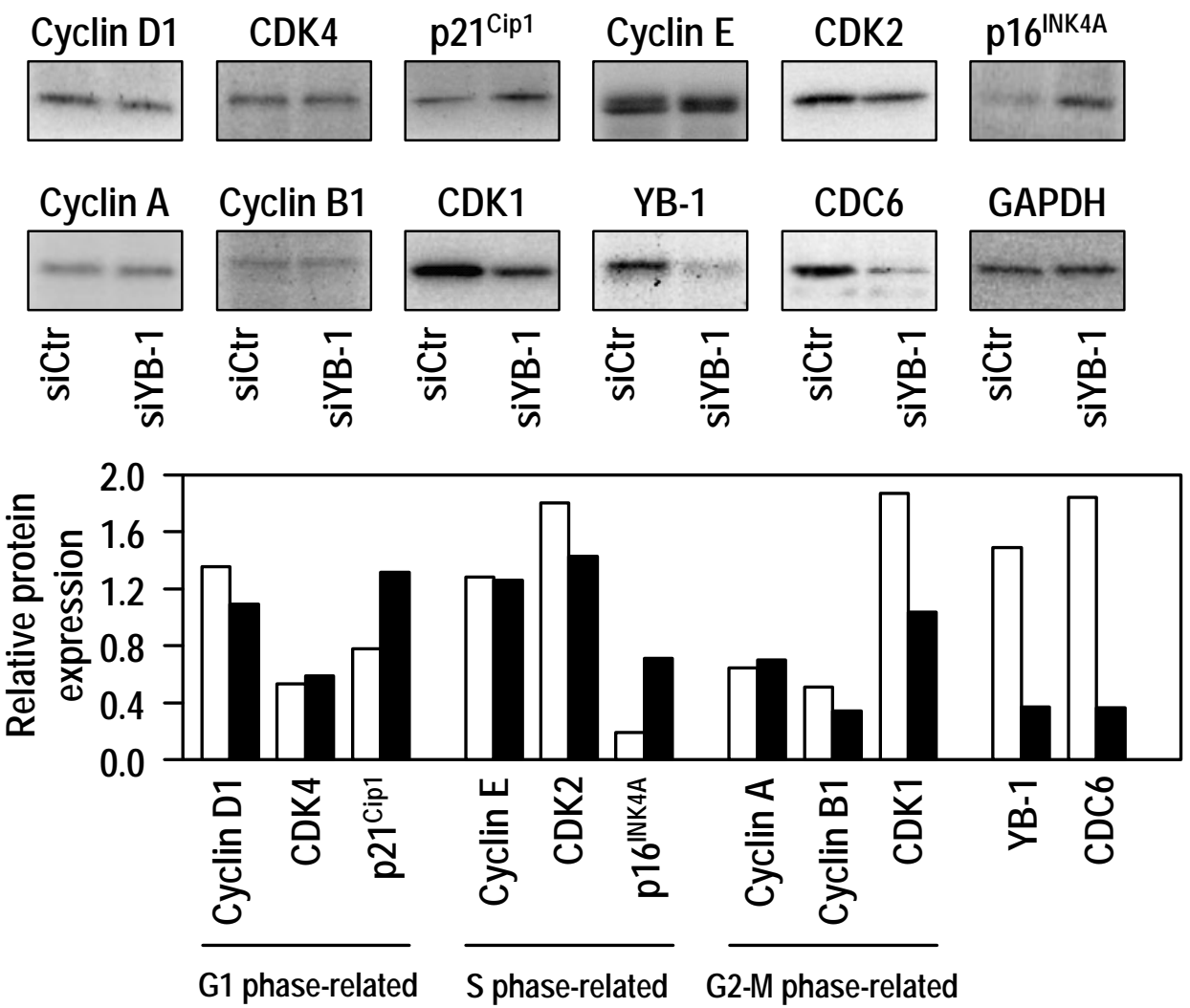
Figure 3C, D, E, F

C

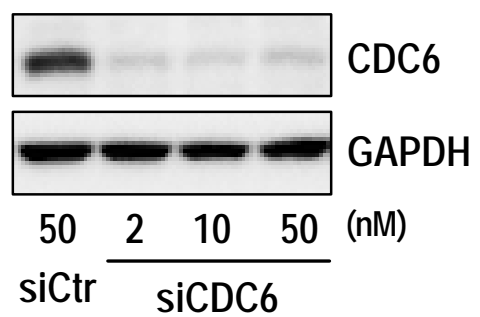

E

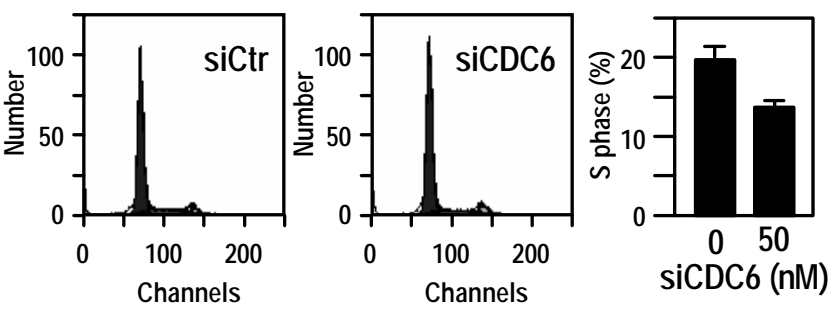

F

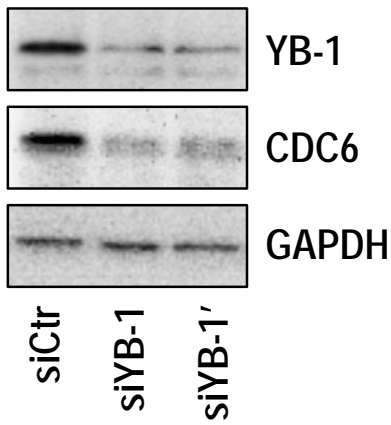

D

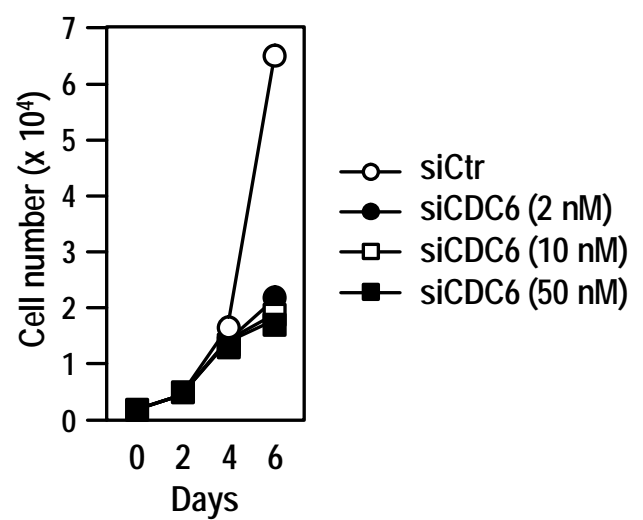


Figure 4

A

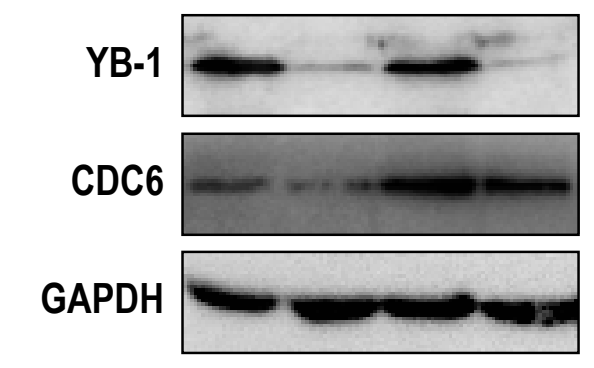

siControl +-+-

siYB-1 - + - +

Vector ++--

CDC6 - -++

C

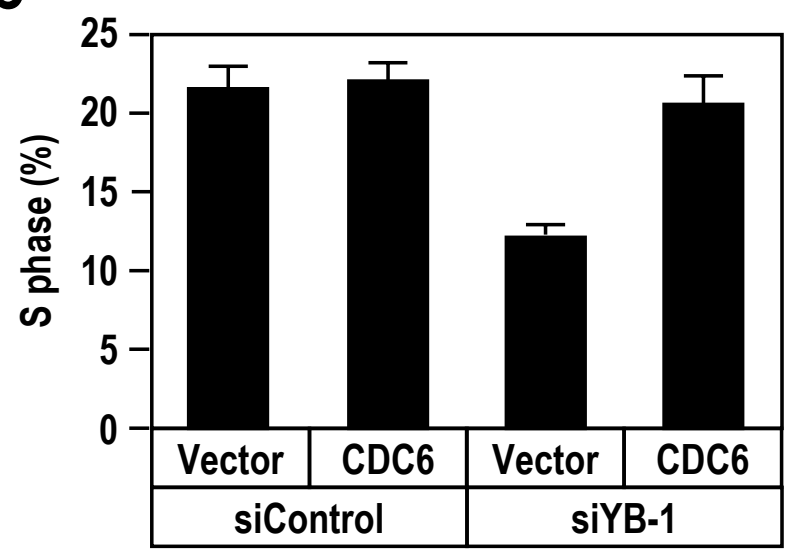

E

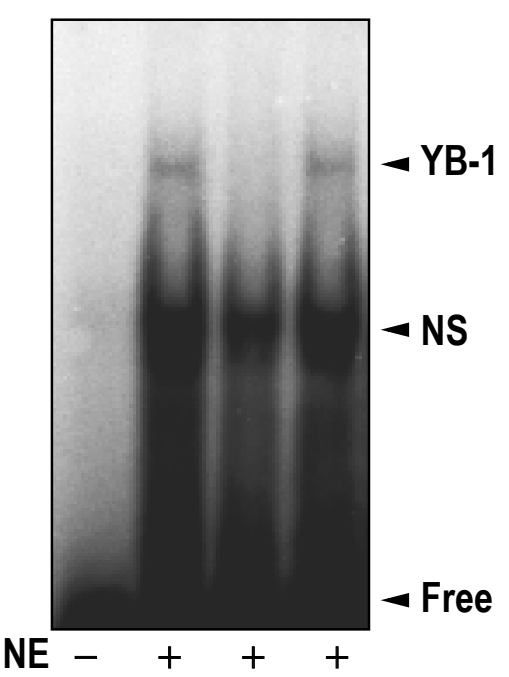

Wt oligo - - + -

Mt oligo - _ _ +
B

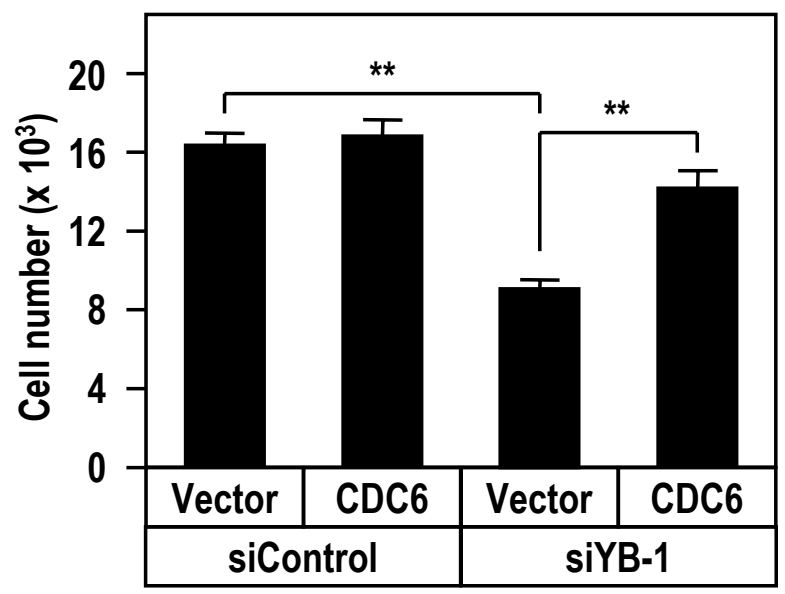

D

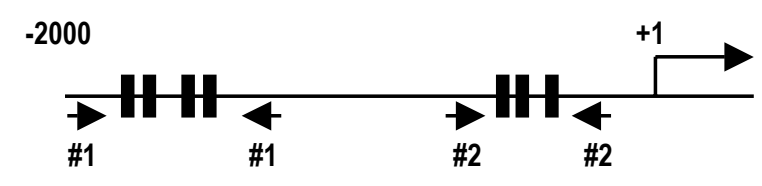

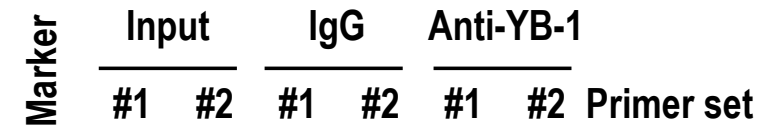

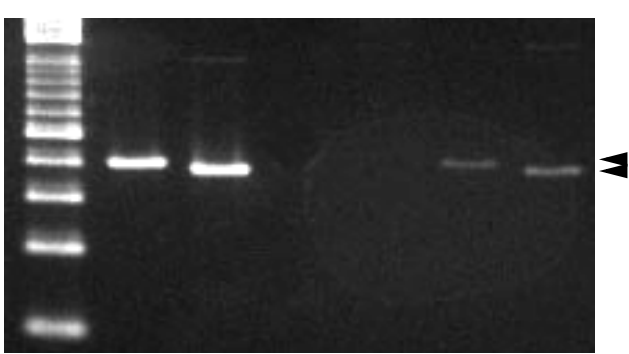


Figure 5

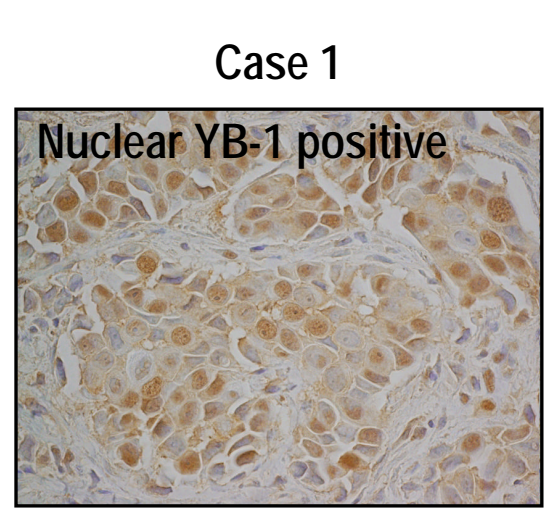

Case 2
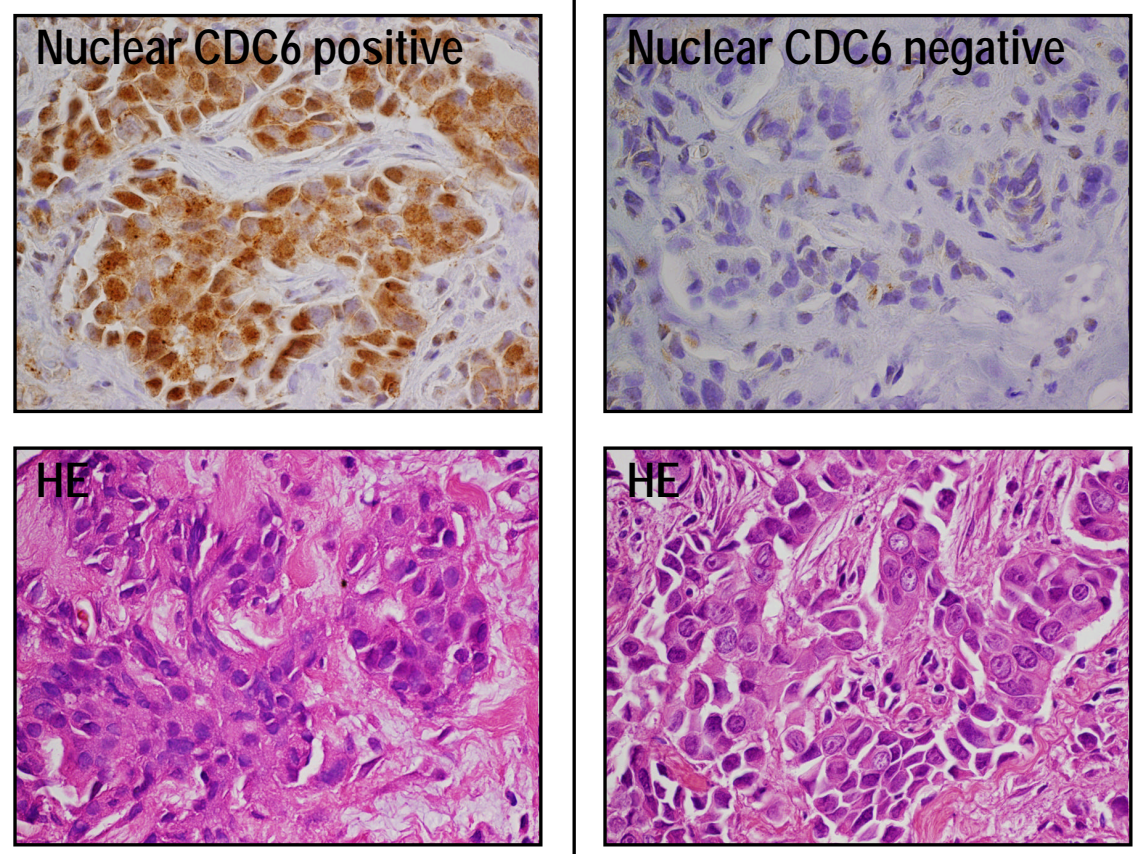